\title{
Formulation of a fast-dissolving oral film using gelatin and sodium carboxymethyl cellulose
}

Abstract

Background and objective: Orally disintegrating film is a solid dosage form made as an alternative for tablets for pediatric and geriatric patients who have difficulty in swallowing. These formulations are designed to dissolve in the mouth rapidly upon contact with saliva. This study aimed to prepare a thin oro-dispersible film base that can withstand handling in which a drug can be incorporated to provide a new dosage form.

Methods: The solvent casting method was used to prepare the films, in which the ingredients were mixed, dissolved, and cast in a Petri dish. Then, they were left to dry in the oven overnight. Different concentrations of each of the two polymers alone and combined in different ratios were compared using different concentrations of plasticizer.

Results: Successful, transparent films were prepared from gelatin and glycerin. A combination of $70 \%$ gelatin and $30 \%$ sodium carboxymethyl cellulose with glycerin formed an acceptable film having white color. The film forming capacity of sodium carboxymethyl cellulose alone was not good. All films were tearing and not well formed. All films that contain polyethylene glycol were brittle. Both superdisintegrants reduced the disintegration time for both films, but kyron was more effective than sodium starch glycolate.

Conclusion: A successful oral film was prepared using different types of polymers, which is suitable for incorporating a potent drug to form a new dosage form that is easily portable and does not require water for swallowing.

Keywords: Fast dissolving oral film; Gelatin; Sodium carboxy methyl cellulose; Solvent casting method.

\section{Introduction}

The oral drug delivery system is the most common and acceptable route of drug administration because of easy ingestion, patient compliance, and lack of pain. However, the most evident drawback of its difficulty of swallowing, especially for pediatric, geriatric, and nauseous patients causing patient incompliance. ${ }^{1}$ To overcome this problem, fast dissolving oral drug delivery systems such as orodispersible tablets and fast dissolving oral strips were developed. This was first developed in the late 1970s. ${ }^{2}$ The orally disintegrating film is a thin film with a thickness of $1-10 \mathrm{~mm}$ and an area of $1-20 \mathrm{~cm}^{2} .{ }^{3}$ These formulations are designed to dissolve in the mouth rapidly upon contact with saliva. In these films, the hydrophilic polymer is used as the base for the film. Other excipients are added as required, like plasticizer, colorant, and flavor. ${ }^{4}$ This type of film was originally made as a mouth refreshing, but then pharmacological ingredients were added to produce a new dosage form. The film could dissolve within a few seconds to one minute, releasing the pharmacologically active ingredient with other inactive ingredients, which can mainly be swallowed with saliva to be absorbed in the gastrointestinal tract (GIT). ${ }^{5}$ Typically, an oral film will contain $1-25 \% \mathrm{w} / \mathrm{w}$ of the active drug ingredient. ${ }^{5}$ Different types of

${ }^{1}$ Department of Pharmaceutical Sciences, College of Pharmacy, Hawler Medical University, Erbil, Iraq.

* Correspondence: jwan.ahmed@hmu.edu.krd 
hydrophilic polymers or a combination of different polymers can be used as a base for the film. The film should be tough enough to withstand handling. ${ }^{5}$ The amount of the polymer should be typically $40-50 \%$ $\mathrm{w} / \mathrm{w}$ of the film. ${ }^{4}$ Examples of polymers used are pullulan, gelatin, ${ }^{5}$ hydroxy propyl methyl cellulose (HPMC), carboxy methyl cellulose (CMC), maltodextrins, and sodium alginate. ${ }^{5}$ In order to improve the mechanical properties of the film, it is necessary to add a suitable type of plasticizer. ${ }^{6}$ It can improve the tensile strength and elongation of the film. ${ }^{6}$ It is required to add $0-20 \% \mathrm{w} / \mathrm{w}$ of plasticezer. ${ }^{4}$ Examples of plasticizer include glycerol, di-butylpthallate, and polyethylene glycols. ${ }^{7}$ All other excipients like fillers, colorants, flavoring, saliva stimulating agents will comprise $0-40 \%$ of the film formulation. ${ }^{4}$ Advantages of fast dissolving oral film (FDO) includes ease of swallowing for geriatric and pediatric patients, suitability for patients having difficulty swallowing, no need of water for administration, easily portable, accurate dosing compared to suspensions, ${ }^{4}$ fast onset of action, fast absorption, and improved patient compliance. ${ }^{5}$ However, there are still some limitations for this relatively new dosage form, such as the inability to incorporate high doses of medicine, which should be between 1-30 mg. Some technical manufacturing limitations include difficulty in achieving dose uniformity, film thickness, and expensive packaging. ${ }^{2}$ Many patents have been achieved in this area. WAFERTAB is a patented system for its unique process in preparing the thin film with drug loading; this can be for oral and topical application. ${ }^{3}$ FOAMBURST is another patented technic granted in 2004 in which capsule is made from foamed film. A film that has a honeycomb structure is made by blowing gas into the film during production. This special honeycomb structured capsule is light and dissolves rapidly, resulting in a melt in the mouth sensation. $^{3} \quad X$ Gel film technology is developed by Bio-progress. ${ }^{3}$ WOWTAB tablet refers to "without water tablet," which is developed by Yamanouchi Pharmaceutical Co. Itd., Japan. This tablet is sufficiently hard before wetting with saliva, but becomes soft and disintegrates or dissolves within 15-20 seconds upon contact with saliva. ${ }^{5}$ Recently many FDO formulations are prepared for different medicines. The fast dissolving oral film of bisoprolol fumarate is prepared using hydroxyl propyl methyl cellulose (HPMC) and maltodextrin as film forming polymers and EG 400 as plasticizer, using the solvent casting method. ${ }^{8}$ In this study, an oral fast dissolving film base was prepared using gelatin and sodium carboxy methyl cellulose (SCMC) as film forming polymers and glycerin and polyethylene glycol 400 as plasticizers. This base will be a novel dosage form in which a potent drug that is suitable for oral administration can be incorporated to form a new dosage form. This study aimed to find the best concentration for each polymer including gelatin and SCMC to form a film with acceptable thickness and strength to withstand handling, comparing the film forming capacity of gelatin and SCMC, find the best concentration for each plasticizer including glycerin and polyethylene glycol (PEG 400) that can give enough elasticity to the films with each of the selected polymer, find the best concentration of combined polymers to form a successful film, and reduce the disintegration time of the films by using sodium starch glycolate (SSG) and kyron as super disintegrants and comparing their effectiveness.

\section{Methods}

\section{Materials:}

The materials used are SCMC, gelatin, glycerin, PEG 400,SSG, kyron, mannitol, sodium saccharin, and citric acid, which are laboratory grade and were provided by the College of Pharmacy of Hawler Medical University. Distilled water was used throughout the experiment.

\section{Method:}

Solvent casting method was used for the 
preparation of ODF. ${ }^{9}$ Ingredients used for the preparation of the film, including polymer, plasticizer, super disintegrant, sodium saccharin, citric acid, and mannitol, were accurately weighed and mixed with $30 \mathrm{ml}$ of distilled water. The mixture was mixed using a magnetic stirrer and heated to $40^{\circ} \mathrm{C}$ for one hour. The homogenous viscous solution was poured into a plastic Petri dish and then placed in the oven and left overnight at $40^{\circ} \mathrm{C}$ to dry.

Calculation for the ingredients:

The polymers were used in three different concentrations, which are 40,45 , and $50 \%$ $\mathrm{w} / \mathrm{w}$. Also, three different concentrations were used for the plasticizer, which are 10, 15, and $20 \% \mathrm{w} / \mathrm{w}$. The other ingredients were used, as shown in Table 1. In general, 36 formulations were prepared using different concentrations of two types of polymers and plasticizers (Table 2). Five more formulas were prepared using combinations of the polymers (Table 3 ).

Table 1: Concentration of the ingredients in the film formulation.

\begin{tabular}{lc}
\hline Compound & $\% w / w$ \\
\hline Polymer & $40,45,50$ \\
Plasticizer & $10,15,20$ \\
Sodium saccharin & 5 \\
Citric acid & 5 \\
Mannitol & qs. \\
\hline
\end{tabular}

Table 2: Concentration of the ingredients for the nine basic formulations.

\begin{tabular}{lccccccccc}
\hline Ingredient & BF1 & BF2 & BF3 & BF4 & BF5 & BF6 & BF7 & BF8 & BF9 \\
\hline Polymer (HPMC, gelatin) & $40 \%$ & $40 \%$ & $40 \%$ & $45 \%$ & $45 \%$ & $45 \%$ & $50 \%$ & $50 \%$ & $50 \%$ \\
Plasticizer (glycerin, PEG 400) & $10 \%$ & $15 \%$ & $20 \%$ & $10 \%$ & $15 \%$ & $20 \%$ & $10 \%$ & $15 \%$ & $20 \%$ \\
Sodium saccharin & $5 \%$ & $5 \%$ & $5 \%$ & $5 \%$ & $5 \%$ & $5 \%$ & $5 \%$ & $5 \%$ & $5 \%$ \\
Citric acid & $5 \%$ & $5 \%$ & $5 \%$ & $5 \%$ & $5 \%$ & $5 \%$ & $5 \%$ & $5 \%$ & $5 \%$ \\
Mannitol & qs & qs & qs & qs & qs & qs & qs & qs & qs \\
\hline
\end{tabular}

Table 3: Concentration for the combination formulas.

\begin{tabular}{lcccc}
\hline Formulas & SCMC \% w/w & Gelatin \% w/w & Glycerin \% w/w & PEG $\mathbf{4 0 0} \%$ w/w \\
\hline F37 & 25 & 25 & & 20 \\
F38 & 25 & 25 & 20 & \\
F 39 & 12.5 & 37.5 & & 20 \\
F 40 & 37.5 & 12.5 & & 20 \\
F 41 & 12.5 & 37.5 & 20 & \\
\hline
\end{tabular}

SSG and kyron, (6\%) were added to the successful formulations as superdisintegrants. 


\section{Evaluation of oral film}

Since oral dissolving films are new dosage forms, no standard evaluation tests are known in the pharmacopeias. Therefore, a set of in vitro evaluation tests was selected from the literature.

1- Visual inspection: the films were inspected visually for their homogeneity, transparency, flexibility, peel ability, and surface texture. ${ }^{10}$

2- Thickness uniformity of the films: this was done by using a digital compass (Vernier caliper). The thickness of the film is an indication of the content uniformity.

3- Folding endurance: this is determined by folding the strip at the same place back and forth repeatedly fifty times. The number of times the film is folded without breaking is determined as the folding endurance of the film. ${ }^{6}$

4- In vitro disintegration time: modified disintegration time test was used. In a small sized beaker containing $10 \mathrm{ml}$ of distilled water at $37^{\circ} \mathrm{C}$, a piece of $2 \mathrm{~cm}^{2}$

film was carefully put in the center. The film was observed and the time measured when the film starts to disintegrate. ${ }^{10}$ This was repeated four times.

\section{Statistical analysis}

All experiments were performed in triplicates, and values were expressed as mean \pm standard deviations. Statistical significance was assessed using one-way analysis of variance (ANOVA) and student t-tests, as appropriate. Values with $P<0.05$ indicate that the difference is statistically significant.

\section{Results}

A total of 41 films were prepared with different concentrations of polymer and plasticizer to find successful films. From all the formulated films, only two were successful, F 36 and F 41. The results for the formation and appearance of films are listed in Table 4.

Table 4: Results for the properties of the prepared films.

\begin{tabular}{|c|c|c|}
\hline Formulas (polymer + plasticizer) & Film appearance & Peelability and brittleness \\
\hline F1 (SCMC 40\% +PEG 10\%) & $\begin{array}{c}\text { Film formed, white in color and } \\
\text { rough surface }\end{array}$ & Sticky cannot be removed \\
\hline F2 (SCMC 40\% +PEG 15\%) & $\begin{array}{l}\text { Film formed with white color and } \\
\text { rough surface }\end{array}$ & Peelable, but brittle \\
\hline F3 (SCMC 40\% +PEG 20\%) & $\begin{array}{l}\text { Film formed with white color and } \\
\text { rough surface }\end{array}$ & Sticky and brittle \\
\hline F4 (SCMC 45\% +PEG 10\%) & $\begin{array}{c}\text { Film formed with white color and } \\
\text { rough surface }\end{array}$ & Sticky, and brittle \\
\hline F5 (SCMC 45\% +PEG 15\%) & $\begin{array}{c}\text { Film formed with white color and } \\
\text { rough surface }\end{array}$ & Peelable and a little brittle \\
\hline F6 (SCMC 45\% +PEG 20\%) & $\begin{array}{l}\text { Film formed with white color and } \\
\text { rough surface }\end{array}$ & Sticky and brittle \\
\hline F7 (SCMC 50\% +PEG 10\%) & $\begin{array}{l}\text { Film formed with white color and } \\
\text { rough surface }\end{array}$ & Sticky and brittle \\
\hline F8 (SCMC 50\% +PEG 15\%) & $\begin{array}{l}\text { Film formed with white color and } \\
\text { rough surface }\end{array}$ & Very sticky \\
\hline F9 (SCMC 50\% +PEG 20\%) & $\begin{array}{l}\text { Film formed with white color and } \\
\text { rough surface }\end{array}$ & Easily peelable but very brittle \\
\hline F10 (SCMC $40 \%+$ glycerin $10 \%)$ & $\begin{array}{l}\text { Film not well formed, with white } \\
\text { color and rough surface }\end{array}$ & Sticky \\
\hline F11 (SCMC $40 \%+$ glycerin $15 \%)$ & $\begin{array}{l}\text { Film not well formed, with white } \\
\text { color and rough surface }\end{array}$ & Sticky \\
\hline F12 (SCMC $40 \%+$ glycerin $20 \%)$ & $\begin{array}{l}\text { Film not well formed, with white } \\
\text { color and rough surface }\end{array}$ & Sticky \\
\hline F13 (SCMC $45 \%+$ glycerin $10 \%)$ & $\begin{array}{l}\text { Film not well formed, with white } \\
\text { color and rough surface }\end{array}$ & Sticky \\
\hline
\end{tabular}




\begin{tabular}{|c|c|c|}
\hline F14 (SCMC 45\% + glycerin 15\%) & $\begin{array}{l}\text { Film not well formed, with white } \\
\text { color and rough surface }\end{array}$ & Sticky \\
\hline F15 (SCMC $45 \%$ + glycerin $20 \%)$ & $\begin{array}{l}\text { Film not well formed, with white } \\
\text { color and rough surface }\end{array}$ & Sticky \\
\hline F16 (SCMC 50\% + glycerin 10\%) & $\begin{array}{l}\text { Film not well formed, with white } \\
\text { color and rough surface }\end{array}$ & Sticky \\
\hline F17 (SCMC 50\% + glycerin 15\%) & $\begin{array}{l}\text { Film not well formed, with white } \\
\text { color and rough surface }\end{array}$ & Sticky \\
\hline F18 (SCMC 50\% + glycerin $20 \%)$ & $\begin{array}{l}\text { Film not well formed, with white } \\
\text { color and rough surface }\end{array}$ & Sticky but brittle \\
\hline F19 (gelatin 40\% + PEG 10\%) & $\begin{array}{l}\text { Film not well formed, with white } \\
\text { color and rough surface }\end{array}$ & Sticky but brittle \\
\hline F20 (gelatin $40 \%$ + PEG 15\%) & $\begin{array}{l}\text { transparent with smooth surface } \\
\text { film formed }\end{array}$ & Sticky and brittle \\
\hline F21 (gelatin 40\% + PEG 20\%) & $\begin{array}{l}\text { Transparent, smooth and broken } \\
\text { film is formed }\end{array}$ & Sticky and brittle \\
\hline F22 (gelatin $45 \%$ + PEG 10\%) & $\begin{array}{l}\text { Transparent, smooth and broken } \\
\text { film is formed }\end{array}$ & Sticky and brittle \\
\hline F23 (gelatin $45 \%+$ PEG $15 \%$ ) & $\begin{array}{l}\text { Transparent, smooth and broken } \\
\text { film is formed }\end{array}$ & Sticky and brittle \\
\hline F24 (gelatin $45 \%+$ PEG $20 \%$ ) & $\begin{array}{l}\text { Transparent, smooth and broken } \\
\text { film is formed }\end{array}$ & Sticky and brittle \\
\hline F25 (gelatin $50 \%+$ PEG $10 \%$ ) & $\begin{array}{l}\text { Transparent, smooth and broken } \\
\text { film is formed }\end{array}$ & Sticky and brittle \\
\hline F26 (gelatin $50 \%+$ PEG $15 \%$ ) & $\begin{array}{l}\text { transparent with smooth surface } \\
\text { film formed }\end{array}$ & Peelable and brittle \\
\hline F27 (gelatin 50\% + PEG 20\%) & $\begin{array}{l}\text { Transparent, smooth and broken } \\
\text { film is formed }\end{array}$ & Peelable and brittle \\
\hline F28 (gelatin $40 \%+$ glycerin $10 \%)$ & $\begin{array}{l}\text { A yellowish transparent film with } \\
\text { smooth surface is formed }\end{array}$ & Sticky and brittle \\
\hline F29 (gelatin $40 \%+$ glycerin $15 \%$ ) & $\begin{array}{l}\text { A transparent with smooth } \\
\text { surface film is formed }\end{array}$ & Sticky and brittle \\
\hline F30 (gelatin $40 \%+$ glycerin $20 \%$ ) & $\begin{array}{l}\text { A transparent with smooth surface } \\
\text { film is formed }\end{array}$ & Sticky and brittle \\
\hline F31 (gelatin $45 \%+$ glycerin $10 \%)$ & $\begin{array}{l}\text { A transparent with smooth } \\
\text { surface film is formed }\end{array}$ & Sticky and brittle \\
\hline F32 (gelatin $45 \%+$ glycerin $15 \%$ ) & $\begin{array}{l}\text { A whitish with smooth surface film } \\
\text { is formed }\end{array}$ & Sticky and brittle \\
\hline F33 (gelatin $45 \%+$ glycerin $20 \%$ ) & $\begin{array}{l}\text { A transparent with smooth } \\
\text { surface film is formed }\end{array}$ & Sticky and brittle \\
\hline F34 (gelatin $50 \%+$ glycerin $10 \%$ ) & $\begin{array}{l}\text { A transparent with smooth surface } \\
\text { film is formed }\end{array}$ & Sticky and brittle \\
\hline F35 (gelatin $50 \%+$ glycerin $15 \%$ ) & $\begin{array}{l}\text { A transparent with smooth surface } \\
\text { film is formed }\end{array}$ & Sticky and brittle \\
\hline F36 (gelatin $50 \%+$ glycerin $20 \%$ ) & $\begin{array}{l}\text { A transparent with smooth surface } \\
\text { film is formed }\end{array}$ & Peelable and not brittle \\
\hline $\begin{array}{l}\text { F37 combination polymer (SCMC } \\
25 \%+\text { gelatin } 25 \%)+ \text { PEG } 20 \%\end{array}$ & $\begin{array}{l}\text { A yellowish, opaque film with } \\
\text { smooth surface is formed }\end{array}$ & Easily peelable but brittle \\
\hline $\begin{array}{l}\text { F38 combination polymer (SCMC } \\
25 \%+\text { gelatin } 25 \%)+ \text { glycerin } 20 \%\end{array}$ & $\begin{array}{l}\text { A yellowish, opaque film with } \\
\text { smooth surface is formed }\end{array}$ & Sticky \\
\hline $\begin{array}{l}\text { F39 combination polymer (SCMC } \\
12.5 \%+\text { gelatin } 37.5 \% \text { ) + PEG } 20 \%\end{array}$ & $\begin{array}{l}\text { A yellowish, opaque film with } \\
\text { smooth surface is formed }\end{array}$ & Sticky \\
\hline $\begin{array}{l}\text { F40 combination polymer (SCMC } \\
37.5 \%+\text { gelatin } 12.5 \%)+P E G 20 \%\end{array}$ & $\begin{array}{l}\text { A whitish transparent with rough } \\
\text { surface film is formed }\end{array}$ & Sticky \\
\hline $\begin{array}{l}\text { F41 combination polymer (SCMC } \\
12.5 \%+\text { gelatin } 37.5 \%)+ \text { glycerin } 20 \%\end{array}$ & $\begin{array}{l}\text { A whitish transparent with rough } \\
\text { surface film is formed }\end{array}$ & $\begin{array}{c}\text { Peelable, not brittle, soft and } \\
\text { flexible }\end{array}$ \\
\hline
\end{tabular}


Formulation of a fast-dissolving oral film using .......

Zanco J. Med. Sci., Vol. 24, No. (3), December, 2020 https://doi.org/10.15218/zjms.2020.040

Figure 1 below shows the photos for some of the films prepared. For the two successful films, further evaluation tests were done, like thickness and folding endurance. Thickness was measured using
Vernier caliper at ten different places of the film, and the mean and standard deviation were calculated. The results are shown in Table 5.

Table 5: Thickness and folding endurance of the two successful films. Results given as mean \pm SD

\begin{tabular}{lccc}
\hline Test & F36 & F41 & $\boldsymbol{P}$ value $(\boldsymbol{\alpha}=\mathbf{0 . 0 5})$ \\
\hline Thickness & $0.14 \pm 0.010$ & $0.29 \pm 0.050$ & 0.007 \\
Folding endurance & $51 \pm 1.52$ & $38 \pm 4.966$ & 0.012 \\
\hline
\end{tabular}

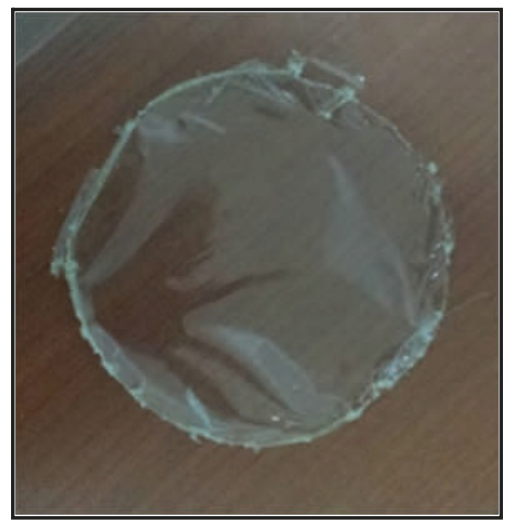

Film containing gelatin $50 \%$ and glycerin $20 \%$ (F 36)

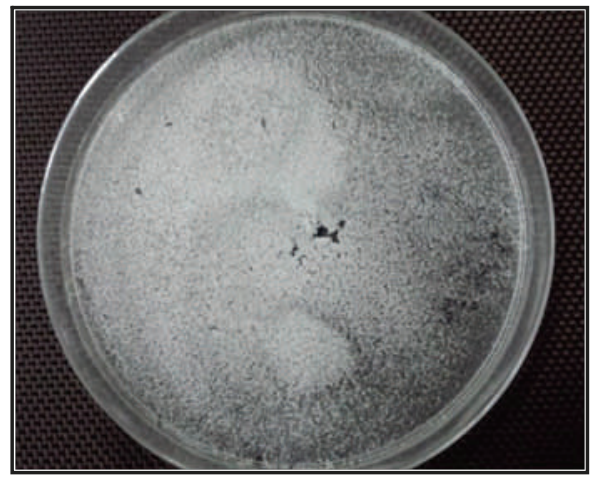

Film containing SCMC and glycerin

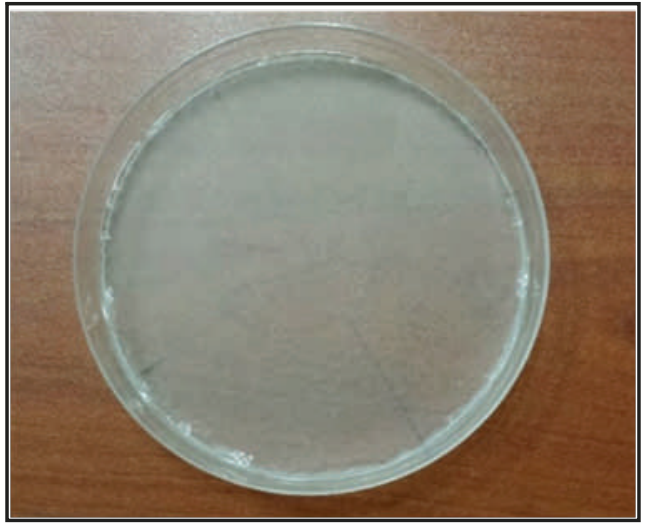

Film containing a combination of gelatin and SCMC (F 41)

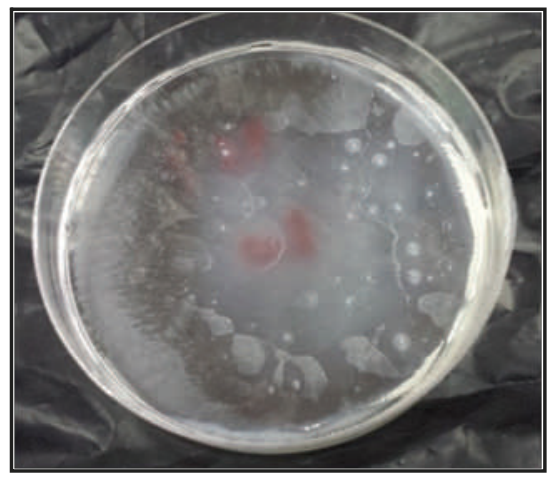

Film containing gelatin and PEG 400

Figure 1: Photos of the formulated films. 
Disintegration time results and kyron in reducing the disintegration

Two different super disintegrants were tested in an attempt to reduce the disintegration time of the films, which included SSG and kyron. The results are shown below in Table 6 . The results shown in Figure 2 compare the efficacy of SSG time of the film containing gelatin $50 \%$ as polymer (F36). In Figure 3, the efficacy of the same super disintegrants in reducing the disintegration time of the film is shown when used with formula 41 in the same concentration.

Table 6: Results for the disintegration time for the two successful formulas using sodium starch glycolate and kyron.

\begin{tabular}{lccc}
\hline Sample & \multicolumn{2}{c}{ Disintegration time (sec) } & P value ( $\alpha=0.05)$ \\
& Added 6\% SSG & 6\% kyron & \\
\hline F 36 & $27 \pm 5.706137$ & $16 \pm 2.861381$ & 0.040 \\
F 41 & $46 \pm 5.356071$ & $16 \pm 1.469694$ & 0.007 \\
\hline
\end{tabular}

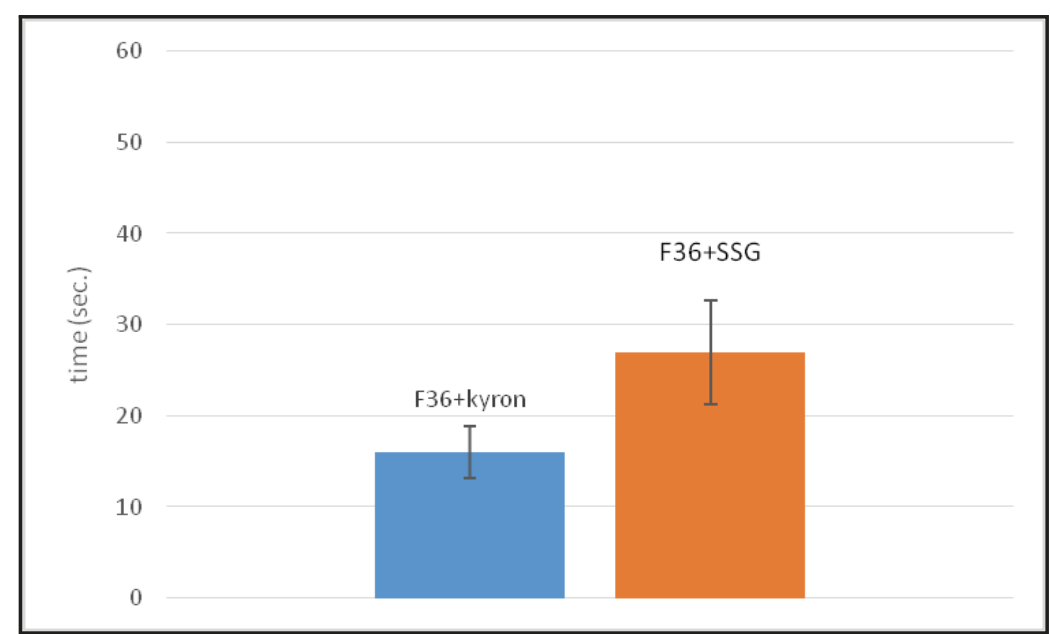

Figure 2: Comparing the disintegration time of the films made with gelatin (F36) containing SSG and kyron.

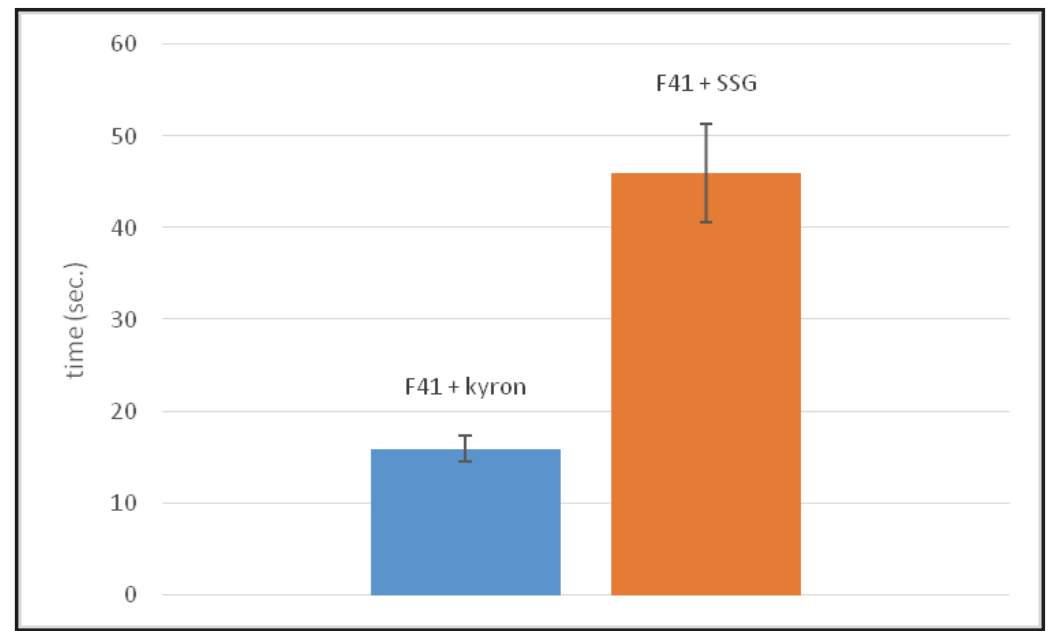

Figure 3: Comparing the disintegration time of the film made with a combination of the polymers SCMC and gelatin (F41) using SSG and kyron. 


\section{Discussion}

In the preparation of the films, a mild increase in temperature $\left(40^{\circ} \mathrm{C}\right)$ was used during mixing in order to increase the solubility of gelatin because it is insoluble in cold water. ${ }^{11}$ Different concentrations of SCMC and gelatin as polymer and glycerin and PEG 400 as plasticizer were tested to prepare the films as shown in Table 4. All films using SCMC and PEG 400 were brittle and sticky to the petri dish except for films containing $15 \%$ PEG and $40 \%$ and $45 \%$ of SCMC, which were peelable. Those two films were unacceptable because of their high tendency to brittleness. Furthermore, PEG 400 was not suitable with SCMC to form an orodispersible film while it could be preferable to use with other polymers like HPMC E15. ${ }^{1}$ Films containing SCMC and glycerin with all the concentrations were brittle and sticky; also, films were not formed. This means that the film forming capacity of polymers can be affected by the plasticizer. Moreover, glycerin is not a suitable plasticizer to be used with SCMC for producing desirable films. The plasticizer has to be compatible with the polymer to improve the mechanical strength of the polymer. Incorporation of an inappropriate amount of plasticizer may lead to the formation of cracked film ${ }^{9}$ as seen in this formula. Films containing gelatin as film forming polymer in all three concentrations and PEG $20 \%$ were all rejected. Therefore, most of the films were broken and sticky. However, when the gelatin and PEG concentration increased, the films were not sticky but still brittle. Thus, the desired film cannot be formed from gelatin and PEG 400 as a film forming polymers. Therefore, a suitable plasticizer had to be selected to improve the mechanical properties of the film. ${ }^{6}$ Films formed from gelatin and glycerin as a polymer were unacceptable because they were very sticky and could not be removed from the Petri dish. However, the film formed from $50 \%$ gelatin and $20 \%$ glycerin (F36) was accepted since the film was easily peelable, transparent with a smooth and un brittle surface. Thus, super disintegrant was added to this formula and was further tested. In order to determine further effects of polymer, a combination of the two polymers were tried. All of the combined formulations were produced from $50 \%$ polymer and $20 \%$ plasticizer, similar to the desirable film concentrations. Moreover, the film prepared from equal ratios of the polymers and PEG as plasticizer was not sticky but unacceptable because the produced film had a higher tendency for brittleness. Furthermore, PEG was replaced with glycerin while the produced film was unacceptable because it was very sticky. Further studies were done in which a combination including $70 \%$ of SCMC polymer and $30 \%$ of gelatin. However, the films formed were very sticky and unacceptable for further investigations. While the films produced with opposite concentrations, i.e., $70 \%$ gelatin and $30 \%$ SCMC and PEG 400 used as a plasticizer, the formed films were sticky to the Petri dish. However, when glycerin was used as a plasticizer (F41), the films were easily peelable from the Petri dish without any degree of brittleness. Furthermore, the evaluation tests were done for the two successful films. Folding endurance was performed to find the mechanical stability of the films. When the films folded in the same place back and forth for fifty times, F36 was still intact, and no sign of braking was apparent. Thus, it was considered acceptable. ${ }^{6}$ However, F41 had a folding endurance of 38 , which shows low mechanical stability of the film (Table 4). Furthermore, the films were quite thin, with a thickness of $0.14 \mathrm{~mm}$ and $0.24 \mathrm{~mm}$ for formula 36 and 41, respectively (Table 5 ). To reduce the disintegration time of the films, super disintegrants were added. In this study, two super disintegrants were tested, which are SSG and kyron, with a concentration of $6 \%$. With formula 36 , Kyron has significantly reduced the disintegration time than SSG $(P<0.05)$ to be only 16 seconds compared to 27 seconds, as shown in Table 6 and 
Figure 2. Similarly, in formula 41 kyron has provided a significantly lower disintegration time being only 16 seconds compared to SSG, which provided a disintegration time of 46 seconds $(P<0.05)$, as shown in Table 6 and Figure 3. Nonetheless, both of them have provided acceptable disintegration. Therefore, kyron is a suitable super disintegrant to be used with both films, while SSG was preferred with films made with gelatin alone but was not acceptable with films containing SCMC. This variance may be due to difference in their mechanism of action as Kyron acts by swelling and capillary action ${ }^{12}$ while SSG works by rapid water uptake. ${ }^{13}$

\section{Conclusion}

The orally disintegrating film is an emerging oral dosage form, which is elegant, easily portable, and does not require water for swallowing. Gelatin with glycerin can produce a successful film base, which can be used as a new dosage form if a suitable active pharmaceutical ingredient is incorporated. However, when SCMC was used with glycerin, suitable films were not formed. This means that the film forming capacity of SCMC was disrupted when mixed with glycerin. PEG 400, when used with either gelatin and SCMC could not produce a successful film, which was not suitable with either form of polymers, but could be suitable with other types of polymer. The combination of the two polymers has produced an acceptable film when used with glycerin. However, the folding endurance was less than required, which could be due to the incompatibility of SCMC with glycerin. Both types of super disintegrants have significantly reduced the disintegration time of the films; nonetheless, kyron was better in reducing the disintegration time for both films.

\section{Competing interests}

The authors declare no competing interests.

\section{References}

1. Galgatte $U$, Khanchandani $S$, Jadhav $Y$, Chaudhari P. Investigation of different polymers, plasticizers and super disintegrating agents alone and in combination for use in the formulation of fast dissolving oral films. Int $\mathrm{J}$ Pharm Tech Res 2013; 5:1465-72.

2. Bala R, Pawar P, Khanna S, Arora S. Orally dissolving strips: A new approach to oral drug delivery system. Int J Pharm Investig 2013; 3:6776.

3. Desu P, Brahmaiah B, Nagalakshmi A, Neelima K, Nama S, Baburao C. An overview on rapid dissolving films. Asian J Pharm Res 2013; 3:1523.

4. Irfana M, Rabel S, Bukhtar Q, Qadirb M, Jabeen F, Khan A. Orally disintegrating films: A modern expansion in drug delivery system. Saudi Pharm J 2016; 24:537-46.

5. Gali A. Fast dissolving dosage forms. Int J Pharm Sci Invent 2013; 2:14-7.

6. Ghodake P, Osmani R, Bhosale R, Harkare B. Mouth dissolving films: Innovative vehicle for oral drug delivery. Int J Pharma Res Rev 2013; 2:417.

7. Arya A, Chandra A, Sharma V, Pathak K. Fast dissolving oral films: An innovative drug delivery system and dosage form. Int. J Chem Tech Res 2010; 2:576-83.

8. Padamwar $\mathrm{P}$, Phasate $\mathrm{P}$. Formulation and evaluation of fast dissolving oral film of bisoprolol fumarate. IJPSR 2015; 6:135-42.

9. Bhyan B, Jangra $S$, Kaur M, Singh $H$. orally fast dissolving oral films: innovation in formulation and technology. Int. J Pharm Sci Rev Res 2011; 9:50-7.

10. Boya D. Formulation and evaluation of oral fast dissolving film of desloratadine. M. Sc. Thesis. Erbil, Iraq: Hawler Medical University; 2014.

11. Gelatin; chemical book, 2017. (Accessed June 21, 2018, at https://www.chemicalbook.com/ ChemicalProductProperty_EN_CB9680379.htm)

12. Lakshmi P, Reddy S, Kishore C, Reddy B. Formulation and evaluation of oral disintegrating tablets of lamotrigine solid dispersions. IJPS 2013; 9:1-12.

13. Mohanachandran $P$, Sindhumol $P$, Kiran $T$. super disintegrants: an overview. Int J Pharm Sci Rev Res 2011; 6:105-9. 